\title{
The mechanics and biomechanics of OASIS POP and incontinence-is active management of labour protective?
}

\author{
Peter Petros ${ }^{1} \cdot$ Mark Richard Beale $^{2,3} \cdot$ Burghard Abendstein $^{4}$ \\ Published online: 13 March 2020 \\ (C) The International Urogynecological Association 2020
}

The mechanics of labour traditionally concern the 3Ps, powers, passages and passengers. Studies on OASIS prevention seem concentrated on minimizing trauma to the passages. A recent study examined the powers (uterine contraction strength). It concluded that passive management of labour was more likely to cause weaker contractions, head deflexion and a larger presenting part, which was more likely to tear the anal sphincter. Comparing third and fourth degree tears (8.17\%) from 100,000 primiparous women against an independent control group with the O'Driscoll active management regime ( $2.5 \%$ tear rate), the authors concluded that a deflexed foetal head (11.2 cm diameter) was more likely to overstretch the vagina, ligaments and external anal sphincter muscles than a flexed head $(9.4 \mathrm{~cm})$.

The study [1] raised further questions: why do only some women undergoing passive management primiparous deliveries suffer OASIS, while most, even with a deflexed head, do not? Do the same mechanics of OASIS carry over to pelvic organ prolapse (POP) and symptom causation?

To answer these questions, we examined the biomechanics of labour/delivery from a dynamic tissue injury perspective. It is evident that a foetal head at full dilatation $(10 \mathrm{~cm})$ will put considerable stress on the cardinal/uterosacral ligaments. What prevents these ligaments from rupturing in the vast majority of cases is that the change in collagen and

Peter Petros

pp@kvinno.com; http://www.integraltheory.org

Burghard Abendstein

burghard@abendstein.at

1 School of Mechanical and Chemical Engineering, University of Western Australia, Perth, WA, Australia

2 POW Hospitals Sydney, Randwick, Australia

3 University of New South Wales, Sydney, Australia

4 Department of Obststrics and Gynecology, Feldkirk Hospital Austria, Feldkirch, Austria glycosaminaoglycans effectively "plasticizes" the ligaments so they stretch rather than rupture. This is necessary, as the inlet and outlet diameters through which the head must pass are no more than $12-13 \mathrm{~cm}$. Collagen fibrils depolymerize to lose up to 93\% of their strength [2]. Pregnancy-associated softening of the uterine cervix occurs $48 \mathrm{~h}$ before labour. The biomechanical changes are extremely complex and not well understood. They can be explained at least partly by qualitative changes in the collagen and proteoglycans, for example an increase in dermatan sulphate. These reactions seem to be mediated by sex steroids by eicosanoids such as prostaglandin E2 and F2a and perhaps by relaxin, leukotrines and cytokines [3]. Fibroblasts, inflammatory cells such as polymorphonuclear leukocytes, eosinophils and macrophages are also of great importance, as is collagenase [3].

However, not all connective tissue is protected from rupture by softening. At the pelvic inlet, dilatation of the cervix to $10 \mathrm{~cm}$ may overstretch the anterior attachments of the cardinal ligaments and pubocervical vaginal fascia to the cervical ring to actually tear them, causing a transverse defect (high cystocele). Approaching the outlet, damage to the pubourethral ligaments may cause stress urinary incontinence; the ATFP may become overstretched to dislocate from the pubic bone or, more likely, its attachment to the ischial spine; collagenous attachments of levators to the symphysis may cause overstretching. As the head descends to pass the pelvic outlet, the perineum must expand for the head to emerge.

Why does the anal sphincter rupture? Whereas ligaments and vaginal fascia with a non-pregnant breaking strain of $300 \mathrm{mg} / \mathrm{mm}^{2}$ and $60 \mathrm{mg} / \mathrm{mm}^{2}$ lose $93 \%$ of their strength to become plastic and expand to accommodate even a deflexed head, striated muscle with a breaking strain of $5 \mathrm{mg} / \mathrm{mm}^{2}$ cannot.

Once the perineum has been breached, the anal sphincter is susceptible to tearing. The maternal exhaustion of a long labour and the associated prolonged second stage do not help the situation. This may require a liftout forceps or vacuumassisted birth, both factors in OASIS causation. 
If the disproportion (for that is what it is) is such as to cause anal sphincter tear, why would the deflexed head on its way down the canal not weaken the connective tissues at all three levels sufficiently to cause a higher incidence of POP, bladder and bowel symptoms in both OASIS and non-OASIS women not only post-natally, but even more so after menopause on the basis that some ligaments may be actually damaged, but have just sufficient collagen to "hang in". Our reasoning is that collagen breakdown accelerates after menopause. [4].

All these questions still need to be answered. Like the canary in the coal mine, an OASIS tear may be but the harbinger of a process causing a higher incidence of POP, bladder and bowel incontinence post-natally and later in life. Any woman with prolonged labour would be vulnerable. It would seem that the O'Driscoll active management regime, which limits labour to $12 \mathrm{~h}$ without increasing the caesarean section rate, may well be protective for not only OASIS, but also POP and incontinence in all women.

Authors contribution $\mathrm{PP}, \mathrm{MB}$ and BA participated in the conception, planning, analyzing and writing up of the work. PP provided the figures.

\section{Compliance with ethical standards}

Conflicts of interest None.

\section{References}

1. Beale M, Petros P. Int Urogynecol J. 2020. https://doi.org/10.1007/ s00192-019-04183-6.

2. Rechberger T, Uldbjerg N, Oxlund $\mathrm{H}$. Connective tissue changes in the cervix during normal pregnancy and pregnancy complicated by a cervical incompetence. Obstet Gynecol. 1988;71:563-7.

3. Uldbjerg N, Ulmsten U. The physiology of cervical ripening and cervical dilatation and the effect of abortifaciunt drugs, in Induction of abortion, Bailliere's Clinical Obst and Gynaecol. Ed Bygdeman M, Baillere Tindall Lond: 1990; 263-281.

4. Sabiullah M, Suleman M, Rehmatunissa R, Ather M, Nasreen N. Urinary hydroxy-proline estimation is cheap biochemical marker of bone turnover in post menopausal women. J Drug Deliv Ther. 2015;5(4):1-2. https://doi.org/10.22270/jddt.v5i4.1155.

Publisher's note Springer Nature remains neutral with regard to jurisdictional claims in published maps and institutional affiliations. 